\title{
TUPAMAROS REVOLUTION - LA REVOLUCIÓN IMPOSIBLE
}

Tupamaros revolution. The impossible revolution.

\author{
Maria Ximena Alvarez*
}

LESSA, Alfonso. Tupamaros revolution - la revolución impossible. Montevideo: Fin de Siglo, 2001.

"La revolución imposible" constituye una obra primordial para quien desea interiorizarse en la historia del movimiento guerrillero urbano MLN-T tupamaros y entender su emergencia y actuación en ese Uruguay de los 60', 70' caracterizado - hasta ese entonces - por ser el lugar donde "nunca ocurría nada".

En los inicios de la década del 60 hicieron sus primeras apariciones públicas, y fueron derrotados en 1972 por la acción de las Fuerzas Conjuntas, siendo la mayoría de sus integrantes presos. Los primeros momentos se caracterizaron por su etapa "Robin Hood", realizando acciones tales como robo de un camión de leche y reparto en barrios carentes, denuncia de corrupción de políticos de época, entre otros. Luego comezaron acciones más "militares" como la muerte del agente norteamericano Dan Mitrione, varios secuestros a figuras de relevancia política nacional e internacional entre los que se encontraba el cónsul brasilero en Montevideo Aloysio Días Gomide, etc. Hoy en día parte de sus ex miembros integran el Frente Amplio ${ }^{1}$ - MPP: Movimiento de Participación Popular; agrupación 26 de marzo- siendo el primero lema más votado dentro del Partido. Algunos de sus ex líderes son miembros del Parlamento - senador José Mujica, diputada Lucía Topolanski, diputado Eutelio Fernández Huidobro.

* Mestranda em História - Universidade Federal do Paraná

1 Partido de izquierda fundado en 1971 que aglutina en su seno todas las tendencias de izquierda política del país. El Gral retirado Líber Seregni (fallecido en julio de 2004) fue uno de sus fundadores y de sus líderes históricos. Actualmente bajo la denominación Encuentro Progresista - Frente Amplio- Nueva Mayoría, está presidido por el Dr Tabaré Vázquez, y se presenta como la tercera tendencia política del país frente a los partidos tradicionales Blanco y Colorado. Desde 1990 está bajo su cargo la Municipalidad de Montevideo. En las recientes elecciones de octubre del 2004 ganaron en el primer turno la presidencia de la República y la mayoría parlamentaria. 
Cómo explicar pues esta nueva modalidad de combate político, siendo que en sus inicios era rechazada la vía electoral? Estas y otras interrogantes son las que trata de abordar este autor a lo largo de su obra.

Alfonso Lessa es uruguayo, nacido en la capital el 13 de enero de 1958. Periodista ampliamente reconocido en el medio nacional, quien ha venido desarrollando durante 25 años su labor periodística en diferentes medios de prensa nacional y coberturas internacionales. Realizó estudios de posgrado, siendo magíster en Ciencias Políticas y Doctor en Diplomacia, además de haber participado de diversos cursos y seminarios en el exterior incluyendo el programa para periodistas de las Naciones Unidas.

Este libro constituye su tesis de maestría de Ciencias Políticas presentado en la Facultad de Ciencias Sociales de la Universidad de la República (Udelar) - Uruguay, cuyo tutor fue el historiador Gerardo Caetano.

Está divido en 36 capítulos - 333 páginas en total - siendo algunos de ellos breves. Si bien están organizados por una cierta sucesión cronológica, no es esto lo que estructura la obra. Se entremezclan capítulos donde prima lo "factual" con otros donde se privilegia las "opiniones" de diferentes actores de la época, presentándose por medio de entrevistas que el mismo autor realizó en diferentes países, lo que le da un mérito mayor por su ardua pesquisa.

Es una obra eminentemente "periodística" que está basada en su amplia mayoría por entrevistas realizadas a tupamaros, ex tupamaros-sobre todo figuras de poco relieve público hoy en día y que sin embargo tuvieron una importancia fundamental para la época- militares, policiales y demás actores. Su trabajo está basado también en una extensa documentación, como archivos del Ejército (de imposible acceso para historiadores) actas tupamaras y demás fuentes, que constituyen otro de los más ricos aportes del libro.

Como el propio autor lo señala, no pretende ser una crónica del Movimiento de Liberación Nacional Tupamaros y sí analizar y entender su surgimiento en el Uruguay de esa época. Lessa descarta la propia singularidad de los hechos históricos nacionales para explicar este fenómeno y privilegia el contexto internacional, primordiamente la revolución cubana. Coincide con el historiador británico Hobsbawm, quien explica los movimientos guerrilleros pos- revolución cubana como um efecto expansivo de la misma, denominándolo "huracán revolucionario".

Ninguno de los factores de la coyuntura uruguaya de entonces permite explicar de manera consistente el surgimiento del foco 
guerrillero, salvo que nos limitemos a la frustración de jóvenes desencantados por los sucesivos fracasos de sus sectores políticos, que decidieron tomar las armas en nombre de un pueblo que permaneció, en mayoría aplastante, ajeno a su opción. Jóvenes inspirados en experiencias ajenas, y arrastrados por el "huracán revolucionario" que solapaba desde La Habana y Sierra Maestra. (p. 323)

De este modo desdeña la importancia que tuvieron en la época, las actuaciones de las gremiales, lo cañeros del departamento de Artigas, las huelgas $\mathrm{u}$ otras acciones de la CNT, sin entender el origen del MLN-T como un fenómeno propiamente uruguayo.

Como el propio título del libro lo señala el autor coincide en destacar que la realización de una revolución en Uruguay - tal como lo había destacado el Che Guevara en su visita al país - era imposible.

La revolución que los Tupamaros querían para el Uruguay era imposible: una sucesión de errores en el análisis sobre la sociedad en la que actuaban, sobre su historia y el papel y peso de varios protagonistas centrales, resultaros decisivos para la caída. A ello se sumaron las marcadas diferencias y contradicciones ideológicas que coexistían dentro del movimiento, producto de su heterogéneo reclutamiento y que se reflejaban en la existencia de objetivos muy diferentes - al menos en el mediano y largo plazo - entre guerrilleros (p. 32)

Lessa situa al MLN-T en el contexto de otros movimientos revolucionarios latinoamericanos (ERP, Montoneros, FARC, PRT, MIR). Los vínculaciones entre el ERP y los Montoneros fueron fundamentales sobre todo el etapa de la dirección en el exilio (1972-1974). Entender la revolución cubana para ver el abismo que había con la realidad del Uruguay - "en la isla gobernaba un régimen dictatorial mientras en Uruguay se asentaba un régimen democrático" (p. 58) - las guerrillas colombianas, la emergencia de movimientos guerrilleros en la Argentina, todos estos países desconocían una tradición de democracia que sí tenía el Uruguay, y por tal motivo hasta los observadores extranjeros veían como abusivo una guerrilla urbana en un país con estas características, en una sociedad de clases media "tan" establecidas. 
Los Tupamaros no son presentados de ningún modo como un cuadro homogéneo. Los que recibieron la "bandera" del movimiento luego de la dictadura, constituyen solamente un sector, el que tiene "voz" pública actualmente. Pero existe otros miembros, tupamaros en el exilio, otros que volvieron a los partidos tradicionales o simplemente que se alejaron de la escena política y que optaron por no integrarse al discurso "tupamaro" o bien fueron ignorados por este. Lessa pone énfasis en esos aspectos olvidados del movimiento tupamaro como sus actividades en el exterior del país. Nos integra la visión de esas a figuras silenciadas en la reconstrucción "oficial del movimiento", como la de Efráin Martínez Platero, ${ }^{2}$ quien rompió su silencio en la entrevista otorgada al autor (Cap. 18,33). Esas disidencias internas y fuertes divergencias de posturas dentro del movimientos, de acuerdo a lo que se desprende de las entrevistas no fueron "exentos de amenazas y condenas a muerte que finalizaron con la fractura" (Cap. 34).

El sector representado por Martínez Platero - los que asumieron la dirección del MLN-T en el exilio (1972-1974) - es considerado por los parlamentaristas (Huidobro, Mujica) como traidores por no haber dado continuidad a la revolución por medio de una contraofensiva del extranjero, siendo que los primeros estaban en el exilio y los segundos en la prisión. Esas tendencias en la interna tupamara proporcionan discursos a posteriori diferentes, presentándo al mismo movimiento hasta objetivos opuestos. Esas contrapuestas posturas que podrían explicarse mejor com un análisis crítico de su mirada selectiva del pasado como explicativa de una situación de la actualidad no es debidamente explotada por el autor. Esa es una de las grandes críticas que desde el ojo del historiador podríamos hacerle a esta obra.

Las entrevistas constituyen una fuente documental fundamental no siendo debidamente analizadas. Estas fueron realizadas a 30 años de que acontecieron los hechos, y por tanto no discrimina y critica ese mirar de "su pasado" que tienen quienes se vieron comprometidos en la época, y hoy en día no ven los acontecimientos del mismo modo, sino con una mirada naturalmente selectiva. Por otra parte muchas de las informaciones proporcionadas en algunos de los casos no son confrontadas por otros documentos que las avalen, y no se indaga sobre la "intencionalidad" de los entrevistados al hacer sus deposiciones. Los militares entrevistados podría procurar relativizar la actuación

2 Fue uno de los jefes históricos del MLN, siendo integrante de la dirección hasta el 1970. Dirigió los grupos de voluntarios guerrilleros uruguayos que trabajaban en Cuba, se relacionó con Fidel Castro, y fue representante de la Junta Coordinadora Revolucionaria sudamericana. Ha optado por el silencio y se lo "olvida" al referirse a los fundadores del movimiento. 
"estrepitosa" de los tupamaros, sobre todo el famoso escape de la Cárcel de Punta Carretas. ${ }^{3}$ Así como exaltar su eficacia destacando el bagaje de información que los militares poseían del movimiento, como también resaltar el carácter terrorista de los mismos y el peligro eminente que representaban para el país - lo que justificaría su actuación represiva de la época.

El discurso tupamaro de hoy es marcado por las diversas tendencias que de él sobrevivieron. Cada cual tentará entenderse en el pasado: tupamaros parlamentarios, el fracaso de una contraofensiva en la época, lo errores del movimiento. La diversidad de visiones es amplia y los silencios y las entrelíneas no fueron explotados a fondo por Lessa.

Podemos concluir que este texto es un excelente aporte para entender más sobre el movimiento tupamaro y su actuación social, política e internacional de la época, dejando el autor abierta la posibilidad que sea el lector que realice sus interpretaciones y reflexiones. Es una investigación muy completa y sugerente que integra personajes no siempre conocidos. Esta obra rompe con la supuesta creencia de que los tupamaros son aquellos que tan frecuentemente aparecen en la prensa y entenderlo como un fenómeno bastante más complejo, que constituyeron y constituyen una etapa importante de la historia del Uruguay contemporáneo.

3 La fuga de la Cárcel de Punta Carretas ( situada en el medio de la ciudad, hoy en día un centro comercial) se efctuó ern setiembre de 1971 y permitrió la evasión de 106 tupamaros y 5 presos comunes. "El Abuso", como se le llamó en la jerga tupamara, dejaba entrever la ineficacia de las autoridades policiales y por otra parte la astucia de los guerrilleros. 